\title{
Clinicopathological Study of Gall Bladder Cancer and its relationship with Gall Stones
}

Poudel R, Singh SK, Basnet S, Devkota H, Adhikari SK

Department of surgery, Chitwan medical college, Bharatpur

Correspondence : Dr. shashi k. singh, Assistant prof., department of surgery

Chitwan medical college, bharatpur

Email: shishasin@gmail.com

\begin{abstract}
:
Introduction: Gall bladder cancer is the most common cancer of the biliary tree and one of the highly malignant tumors with poor prognosis. Although its incidence is low in west, it is common in our part of the world. There are very few studies regarding gall bladder cancer in Nepal. The incidence of gallstones in patients with gall bladder cancer is high. The aim of the study was to evaluate the clinicopathological aspect of the disease in patients with gallbladder cancer and to Asses the incidence of gallstones in patients with gall bladder cancer.
\end{abstract}

Material and Methods:This was a retrospective study carried out in Gl Surgery unit of National Academy of Medical Science, Bir Hospital, Kathmandu, Nepal. All patients diagnosed as gallbladder carcinomas during 12 years period from 2002 to 2014 were included in this study. Their clinical characteristics, laboratory data, tumor histopathology reports were obtained and analyzed using SPSS17.

Results:Total of 47 patients who met inclusion criteria were included in the study. Male to Female ratio was 1:1.8. Age ranged from 32 to 72 years with mean age of 54 . Most common presenting symptom was Pain abdomen (93.6\%) followed by weight loss (51.1\%) and Jaundice (46.8\%). Most common finding on examination was Icterus (42.6\%) followed by palpable gall bladder (34\%) and Hepatomegaly (29.8\%). Gall Stones were seen in $37(72.3 \%)$ patients. Most common histopathology was Adenocarcinoma (93.6\%).

Conclusion: Most of the patient with gall bladder cancer remained asymptomatic until late. Pain abdomen was most common presenting symptom and icterus was most common findings. There was strong association between gall bladder cancer and gallstones. There should be high index of suspicion if patient with gallstones has constant pain in right hypochondrium and has jaundice.

Key Words: Gall bladder cancer, Gallstones, Nepal 